\title{
A Prospective, Open-Label, 12 Week Trial of S-adenosylmethionine in the Symptomatic Treatment of Alzheimer's Disease
}

\author{
Maja L. Rudolph, Michael Rabinoff, Bruce L. Kagan
}

UCLA Neuropsychiatric Institute and Hospital, Los Angeles, USA.

Email: bkagan@mednet.ucla.edu

Received May 25 ${ }^{\text {th }}$ 2011; revised July 25 ${ }^{\text {th }}, 2011$; accepted August 20 ${ }^{\text {th }}, 2011$.

\begin{abstract}
Objective: To determine if treatment with S-adenosylmethionine (SAM-e) might lead to cognitive and behavioral improvement in patients with Alzheimer's disease $(A D)$. Interventions: We conducted a prospective, open-label study of six subjects who were given oral SAM-e over 12 weeks and measured the effects on cognition and behavior. Outcome measures: Outcome measures of cognition and behavior included the Alzheimer's Disease Assessment Scale -Cognitive subscale (ADAS-Cog), Mini-Mental State Examination (MMSE), Behave-AD, Clinical Global Impression Scale (CGI), Hamilton Rating Scale for Depression (HAM-D), informant version, Blessed Dementia Scale to assess activities of daily living (ADL), the Physical Self-Maintainance Scale (PSMS), and the Lawton-Brody IADL Scale to measure instrumental activities of daily living. Results: At study completion, two subjects were "moderately improved" and 4 were "minimally improved" on the CGI. Five subjects improved on the ADAS-Cog by an average of $20 \%$. No significant side effects were reported. Conclusions: In this small open label study, SAM-e appeared to have a beneficial effect in patients with $A D$, but the small subject number didn't provide enough power to show statistical significance. Controlled trials with adequate statistical power to investigate its utility in $A D$ are warranted.
\end{abstract}

Keywords: S-adenosylmethionine, Treatment, Alzheimer's Disease

\section{Introduction}

SAM-e is a key methyl group donor in many important reactions in the nervous system. These reactions involve neurotransmitters, amines, phospholipids, DNA and proteins. This compound is also tightly linked to the folate cycle [1]. Low folate levels have been associated with several psychiatric illnesses, including dementia and depression [2,3], and folate supplementation may enhance recovery in several psychiatric illnesses [4].

SAM-e concentrations have been shown to be decreased in human cerebrospinal fluid from severely depressed patients, from Alzheimer's disease patients [1,5], and in post-mortem brain tissue from Alzheimer's disease patients [6]. Based on these findings, it is possible that treatment with SAM-e might lead to clinical improvement in patients with $\mathrm{AD}$.

"Role of the Funding Source: Pharmavite LLC had no involvement in study design, in the collection, analysis, and interpretation of data, in the writing of this article, or in the decision to submit this paper for publication.
Bottligleri et al. have demonstrated in a very small [ $n$ $=4]$, uncontrolled clinical study with $\mathrm{AD}$ patients that the administration of oral SAM-e for 3 to 5 months (400 mg, 3 times daily) increased plasma and CSF SAM-e concentrations [1,7], and improved measures of cognitive function as well as mood and speed of mental processing $[8,9]$. Also, SAM-e decreases the increased membrane fluidity seen in AD brain and aged rat brain [10,11]. Cohen et al. [10] studied the effects of SAM-e administration on 4 patients with Alzheimer's dementia. Those patients received 200 to $400 \mathrm{mg}$ IV daily for 14 days. There were no changes in cognitive function or mood state, perhaps due to the short duration of the study.

Based on their review of the literature, Shea and Chan conclude that preclinical and clinical findings demonstrate that dietary supplementation with S-adenosyl methionine alleviates a variety of risk factors and hallmarks of Alzheimer's disease, and that nutritional supplementation with S-adenosyl methionine may represent an important augmentation for therapy in Alzheimer's disease 
[12].

The aim of this study was to determine if SAM-e would lead to cognitive and behavioral improvement in patients with AD. SAM-e appears to be a relatively benign medication with few side effects [13]. It has been widely used for the treatment of depression and arthritis in Europe for more than a decade [7]. It is now available in the United States as a food supplement.

\section{Materials and Methods}

Seven Caucasian men and women in the 59-90-year old age range with a Diagnostic and Statistical Manual [14] (DSM-IV) diagnosis of possible or probable Alzheimer's disease were recruited from the UCLA Alzheimer's Disease Center and the community. One subject was noncompliant with treatment, and was dropped from the study. All subjects received a physical examination, psychiatric evaluation, EKG, and routine screening laboratory tests. Subjects with any psychiatric (bipolar disorder, anxiety, psychosis, substance abuse, and current depression), neurological or medical condition which could affect cognitive functioning were excluded. Subjects were allowed to take concomitant psychotropic medications such as antipsychotics, benzodiazepines and acetylcholinesterase inhibitors, but needed to have been stable on them for one month prior to starting the study medication. All subjects had a caregiver available to monitor and administer medication and to accompany them to each clinical visit. Outcome measures of cognition and behavior were administered at baseline and again at 12 weeks. These were: Alzheimer's Disease Assessment Scale-Cognitive subscale (ADAS-Cog) [15], Mini-Mental State Examination (MMSE) [16], Behave-AD [17,18], Clinical Global Impression Scale (CGI), Hamilton Rating Scale for Depression (HAM-D) [19], informant version, Blessed Dementia Scale to assess activities of daily living (ADL) [20], the Physical Self- Maintainance Scale (PSMS), and the Lawton-Brody IADL Scale to measure instrumental activities of daily living [21]. Subjects were given 1200 mg of oral SAM-e each day. To ease compliance, subjects were given the choice of taking $400 \mathrm{mg}$ tid or 600 $\mathrm{mg}$ bid. The treatment trial was 12 weeks in duration. To ensure compliance with SAM-e, during each contact caregivers were questioned regarding any missed doses and subjects brought any remaining SAM-e with them to the last visit. The UCLA Medical Institutional Review Board approved this study. SAM-e medication was supplied by Pharmavite LLC, P.O. Box 9606, Mission Hills, CA 91346.

\section{Results}

No subjects reported significant side effects. Five sub- jects improved on the ADAS-Cog by an average of $20 \%$. The sixth declined by 6\% (See Table 1). Two subjects were "moderately improved" and 4 were "minimally improved" on the CGI. MMSE scores showed little change. Two subjects decreased by 1 point, 1 improved slightly, and 2 were unchanged. Scores on the PSMS showed little change, IADLs were unchanged or improved in all but one subject. Activities ADLs (Blessed) were unchanged or improved in all but one subject. Ham-D scores showed no change or slight improvement. No one developed Parkinsonism on SAM-e (See Table 1).

\section{Discussion}

The results of this small study suggest the possibility that SAM-e may improve function in AD, particularly in cognition. All subjects showed at least minimal improvement, and two improved moderately. No one worsened significantly in cognition or behavior. The ADAS-Cog is the scale most often used to assess cognition in $A D$ clinical trials. It assesses multiple areas of cognition, including memory, naming, constructional and ideational praxis, orientation, and spoken language abilities. It is a more sensitive indicator of change than is the MMSE. No significant side effects were reported, which is noteworthy as the cholinesterase inhibitors, the current mainstay of treatment, are often limited by side effects [22,23].

Our results are similar to those of Bottiglieri et al. [7]. The Cohen et al. [10] study may have failed to show an effect due to its relatively brief duration (14 days). SAMe downregulates presenilin 1 gene expression and beta amyloid production in neuroblastoma cells [24]: this could underlie at least part of SAM-e's clinical effects.

Limitations to this study include its un-blinded nature, small sample size, lack of control group, and its short length. We cannot exclude a practice effect on the ADASCog, although this has not been previously observed with this test in this population.

\section{Conclusions}

Table 1. Baseline and 12 week ADAS-Cog patient scores.

\begin{tabular}{ccccc}
\hline SUBJECT & Sex & Age & $\begin{array}{c}\text { ADAS-Cog } \# 1 \\
\text { First Admin }\end{array}$ & $\begin{array}{c}\text { ADAS-Cog \#2 } \\
\text { Second Admin }\end{array}$ \\
\hline$\# 1$ & $\mathrm{~F}$ & 84 & 15 & 13 \\
$\# 2$ & $\mathrm{~F}$ & 59 & 17 & 18 \\
$\# 3$ & $\mathrm{~F}$ & 90 & 10.33 & 7.33 \\
$\# 4$ & $\mathrm{M}$ & 86 & 18 & 13.33 \\
$\# 5$ & $\mathrm{M}$ & 78 & 15 & 12 \\
$\# 6$ & $\mathrm{~F}$ & 79 & 16 & 9 \\
\hline
\end{tabular}

Mean across Subjects 15.22 12.11; Age Range: 59 - 90; Age Mean: 79.33; *ADAS-Cog: Alzheimer's Disease Assessment Scale - Cognitive Subscale. 
In this small open label study, SAM-e appeared to have a beneficial effect in patients with $\mathrm{AD}$, but the small subject number didn't provide enough power to show statistical significance. Controlled trials, with larger subject numbers to provide adequate statistical power, to investigate the use of S-adenosylmethionine in patients with $\mathrm{AD}$ are warranted, as better treatments for $\mathrm{AD}$ are clearly needed.

\section{Acknowledgements}

We are grateful to Jennifer Dunkin, Ph.D. and Gary Small, M.D., for study review, to Doris Finck for manuscript preparation, and to Pharmavite, LLC, P.O. Box 9606, Mission Hills, CA 91346, for supplying S-adenosylmethionine tablets. This work was supported by a grant from the Hartford Foundation to Maja L. Rudolph. The UCLA Clinical Research Center provided space and laboratory testing (NIH Grant \#MO1RR00865).

\section{Author Disclosure Statement}

There are no commercial associations with any of the authors that might create a conflict of interest in connection with this manuscript. BLK is a member of the scientific advisory board and has equity in Methylation Sciences, Inc.

\section{REFERENCES}

[1] T. Bottiglieri, P. Godfrey, T. Flynn, et al., "Cerebrospinal Fluid S-Adenosylmethionine in Depression and Dementia: Effect of Treatment with Parenteral and Oral S-adenosylMethionine," Journal of Neurology, Neurosurgery and Psychiatry, Vol. 53, 1990, pp. 1096-1098. doi:10.1136/jnnp.53.12.1096

[2] M Carney, "Serum Folate Values in 423 Psychiatric Patients,” British Medical Journal, Vol. 4, No. 5578, 1967, pp. 512-516. doi:10.1136/bmj.4.5578.512

[3] E. Reynolds, J. Preece, J. Bailey, et al., "A Folate Deficiency in Depressive Illness,” British Journal of Psychiatry, Vol. 117, No. 538, 1970, pp. 287-292.

[4] P. S. Godfrey, B. K. Toone, M. W. Carney, et al. "Enhancement of Recovery from Psychiatric Illness by Methylfolate,” Lancet, Vol. 336, No. 8720, 1990, pp. 953954.

[5] T. Bottiglieri, E. Reynolds, B. K. Toone, et al., "CSF Sadenoslymethionine in Neurospcyhatirc Disorders," Lancet, Vol. 338, No. 8759, 1991, p. 121.

[6] L. Morrison, D. Smith and S. Kish. "Brain S-adenosylmethionine Levels Are Severely Decreased in Alzheimer's Disease," Journal of Neurochemistry, Vol. 67, No. 3, 1996, pp. 1328-1331. doi:10.1046/j.1471-4159.1996.67031328.x

[7] T. Bottiglieri, K. Hyland and E. Reynolds. "The Clinical Potential of Ademetionine (S-Adenosylmethionine) in
Neurological Disorders,” Drugs, Vol. 48, No. 2, 1994, pp. 137-155.

[8] E. Reynolds, M. Camey, B. Toone, et al., "Transmethylation and Neuropsychiatry,” In: J. M. Mato, Ed., Proceedings of the 1st Conference on Biochemical, Pharmacological and Clinical Aspects of Transmethylation, Jarpyo, Madrid, 1986, pp. 93-102.

[9] E. Reynolds, P. Godfrey, T. Bottiglieri, et al., "S-adenosylmethionine and Alzheimer's Disease,” Neurology, Vol. 39, Suppl. 1, 1989, p. 397.

[10] B. Cohen, A. Satlin and G. Zubenko. "S-Adenosylmethionine in the Treatment of Alzheimer's Dementia," Journal of Clinical Psychopharmacology, Vol. 8, 1988, pp. 43-47.

[11] M. Cimino, G. Vantini, S. Algeri, et al., "Age-Related Modification of Dopaminergic and Beta-Adrenergic Receptor System: Restoration to Normal Activity by Modifying Membrane Fluidity with S-Adenosylmethionine," Life Sciences, Vol. 34, No. 21, 1984, pp. 2029-2039. doi:10.1016/0024-3205(84)90367-9

[12] T. Shea and A. Chan, "S-Adenosyl Methionine: A Natural Therapeutic Agent Effective against Multiple Hallmarks and Risk Factors Associated with Alzheimer's Disease,” Journal of Alzheimers Disease, Vol. 13, No. 1, 2008, pp. 67-70.

[13] B. Kagan, D. Sultzer, N. Rosenlicht and R. Gerner, “Oral S-adenosylmethionine in Depression: A Randomized, Double-Blind, Placebo-Controlled Trial," American Journal of Psychiatry, Vol. 147, No. 5, 1990, pp. 591- 595.

[14] American Psychiatric Association, "Diagnostic and Statistical Manual of Mental Disorders," 4th Edition, American Psychiatric Association Press, Washington DC, 1994.

[15] W. Rosen, R. Mohs and K. Davis, “A New Rating Scale for Alzheimer's Disease,” American Journal of Psychiatry, Vol. 141, No. 11, 1984, pp. 1356-1364.

[16] M. Folstein, S. Folstein and P. McHugh, "Mini-Mental State: A Practical Method for Grading the Cognitive State of Patients for the Clinician," Journal of Psychiatric Research, Vol. 12, No. 3, 1975, pp. 189-198. doi:10.1016/0022-3956(75)90026-6

[17] B. Reisberg, “Alzheimer’s Disease,” In: E. Sadavoy, L. Lazarus, L. Jarvik, and G. Grossberg , Eds., Comprehensive Review of Geriatric Psychiatry II, American Psychiatric Press, Inc., Washington D.C., 1996, p. 430.

[18] B. Reisberg, J. Borenstein, S. Salob, et al., "Behavioral Symptoms in Alzheimer's Disease: Phenomenology and Treatment," Journal of Clinical Psychiatry, Vol. 48, Supplement 5, 1987, pp. 9-15.

[19] M. Hamilton, “A Rating Scale for Depression,” Journal of Neurology, Neurosurgery and Psychiatry, Vol. 23, No. 1, pp. 56-62. doi:10.1136/jnnp.23.1.56

[20] G. Blessed, B. E. Tomlinson and M. Roth, "The Association between Quantitative Measures of Dementia and of Senile Change in the Cerebral Grey Matter of Elderly Subjects," British Journal of Psychiatry, Vol. 114, No. 512, 1968, pp. 797-811. doi:10.1192/bjp.114.512.797 
[21] M. P. Lawton and E. M. Brody, “Assessment of Older People: Self-Maintaining and Instrumental Activities of Daily Living,” Gerontologist, Vol. 9, No. 3, 1969, pp. 179186.

[22] E. Peskind, "Pharmacologic Approaches to Cognitive Deficits in Alzheimer's Disease," Journal of Clinical Psychiatry, Vol. 59, Supplement 9, 1998, pp. 22-27.

[23] G. Small, P. Rabins, P. Barry, et al., "Diagnosis and Treat- ment of Alzheimer Disease and Related Disorders,” Journal of the American Medical Association, Vol. 278, No. 16, 1997, pp. 1363-1371.doi:10.1001/jama.278.16.1363

[24] S. Scarpa, A. Fuso, et al., "Presenilin 1 Gene Silencing by S-Adenosylmethionine: A Treatment for Alzheimer's Disease?” FEBS Letters, Vol. 541, 2003, pp. 145-148. doi:10.1016/S0014-5793(03)00277-1 